\title{
Avaliação da fragilidade ambiental e riscos associados da região metropolitana de Aracaju/ Sergipe
}

\author{
Evaluation of environmental fragility and associated risks of the metropolitan region \\ of Aracaju / Sergipe.
}

\author{
SANTANA ${ }^{1}$, L. B.; ARAÚJO², H. M.
}

leobarsan@gmail.com

\begin{abstract}
Resumo
O presente trabalho teve como objetivo adaptar as propostas metodológicas de Ross (1994) e Crepani (1996, 2001) para novos procedimentos de determinação da fragilidade ambiental e riscos associados, tendo como área de estudo a região metropolitana de Aracaju. Os procedimentos metodológicos consistiram no levantamento das informações bibliográficas sobre as metodologias apresentadas, das informações cartográficas necessárias, organização do banco de dados geográficos em um SIG e posterior cruzamento das informações, culminando com elaboração de mapas temáticos ponderados com pesos variando de 1 (muito baixa fragilidade) até 5 (muito alta fragilidade) que permitiram a confecção do mapa de fragilidade potencial. Identificadas as fragilidades naturais da área em questão (baixa, média e alta), compreendeu-se que as derivações antropogênicas realizadas foram capazes de interferir no fluxo energético que mantém o sistema em funcionamento e estão desencadeando processos degenerativos ao ambiente natural em áreas com fragilidade potencial média e alta, a exemplo das encostas e das margens dos principais rios que drenam a região estudada, suscetíveis a movimentos de massa ou alagamentos, principalmente entre os meses de abril a agosto, períodos de maior precipitação. Tais fenômenos naturais são potencializados pela própria sociedade que ocupa esses locais e sofre os seus efeitos.
\end{abstract}

Palavras-chave: fragilidade, ambiente, Aracaju.

\begin{abstract}
This study aimed to adapt the methodological proposals of Ross (1994) and Crepani (1996, 2001) for new procedures for determining the environmental fragility and associated risks, with the study area the metropolitan area of Aracaju. The methodological procedures consisted of survey of bibliographic information on the methodologies presented, the necessary map information, organization of the geographic database in a GIS and subsequent crossing of information, culminating in the preparation of thematic maps weighted with weights ranging from 1 (very low fragility) to 5 (very high brittleness) that allowed the preparation of potential weakness map. Identified the natural weaknesses of the area in question (low, medium and high) understood that anthropogenic derivations performed were able to interfere with energy flow that keeps the system running and are triggering degenerative processes to the natural environment in areas of potential weakness medium and high, like the slopes and the banks of major rivers that drain the region studied, susceptible to mass movements or flooding, particularly between the months of April to August, the highest rainfall periods. Such natural phenomena are enhanced by the company occupying these places and suffers its effects.
\end{abstract}

Keywords: fragility, environment, Aracaju.

\section{INTRODUÇÃO}

A tecnificação e a sofisticação crescentes dos padrões socioculturais e o aumento demográfico interfere no ambiente natural, e a procura por recursos naturais torna-se mais intensa (ROSS, 2006). Diante desta realidade o homem transformou os espaços naturais para obter destes 
os insumos necessários para a satisfação de suas necessidades, mas tal interferência, deu-se de forma desequilibrada sem levar em conta as limitações naturais relacionadas ao ambiente no qual as atividades antrópicas estão assentadas (ROSS, 1994). A rápida urbanização da população brasileira, a partir da década de 1950, gerou uma desordenada expansão das cidades, sobretudo daquelas que compõem as regiões metropolitanas, representadas na maioria dos casos pelas capitais dos estados (ALMEIDA, 2012). Este autor ainda afirma que as políticas incentivadoras da metropolização superpuseram infraestruturas urbanas a sítios nem sempre adequados a ocupação de áreas susceptíveis a processos naturais perigosos.

Para as metrópoles, a denominação "riscos ambientais urbanos" pode englobar uma grande variedade de acidentes, com distintas dimensões e socialmente produzidos (JACOBI, 2004). Ainda para o mesmo autor

Em seu cotidiano, a população de baixa renda, de uma forma geral, estar mais suscetível aos riscos de enchentes, escorregamentos de encostas com alto grau de declividade, contaminação do solo e das águas e demais acidentes envolvendo atividades de mineração, industriais e outros. Assim, é inegável a íntima relação entre os riscos urbanos e a questão do uso e ocupação do solo, que entre as questões determinantes das condições ambientais da cidade é aquela onde se definem os problemas ambientais de complexo enfrentamento e dialeticamente onde mais se identificam competências de âmbito municipal (JACOBI, 2004, p.170).

A zona costeira de Sergipe, e em especial os municípios pertencentes a região metropolitana de Aracaju não fogem a este quadro, pois o encarecimento do solo urbano empurrou parte da população carente para as bordas da capital sergipana e dos municípios circunvizinhos a exemplo de Nossa Senhora do Socorro, São Cristóvão e Barra dos Coqueiros, além disso as políticas recentes de incentivo à construção de moradias tem modificado a dinâmica espacial desses quatro municípios, resultando atualmente numa área em que formas indesejáveis de ocupação territorial e conflitos múltiplos são identificados.

Em função disto, torna-se cada vez mais urgente o planejamento físico territorial, não só com enfoque socioeconômico, mas, também, ambiental, levando-se em consideração não apenas as potencialidades, mas principalmente a fragilidade das áreas com intervenções antrópicas.

Partindo dessa preocupação o presente trabalho utiliza o conceito das Unidades Ecodinâmicas de Tricart (1977) baseado na Teoria dos Sistemas que parte que na natureza as trocas de energia e matéria se processam através do equilíbrio dinâmico. As Unidades Ecodinâmicas foram classificadas por ele em três categorias: meios estáveis, meios intergrades e meios fortemente instáveis, propondo também a cartografação destas unidades da paisagem através da Carta Ecodinâmica. Nas áreas que prevalece os processos morfogenéticos são entendidas como instáveis, 
enquanto que nas que predominam a pedogênese são as estáveis. Quando há um equilíbrio entre ambos é definida com estabilidade intermediária ou intergrade.

Com base no conceito de ecodinâmica, visando aplicações ao Planejamento Ambiental, Ross (1994) acrescenta novos critérios estabelecendo a análise empírica da fragilidade dos ambientes naturais e antropizados, compreendendo a fragilidade potencial, que relaciona os fatores naturais da paisagem; e a fragilidade emergente, relacionando a fragilidade potencial com a cobertura do solo e as intervenções antrópicas.

Assevera Ross (1994), que a carta de fragilidade potencial indica os graus de fragilidade, sob a ação dos processos morfogenéticos atuantes na paisagem, resultantes da interdependência de alguns dos componentes físico-naturais da paisagem: declividade do terreno, erosividade das chuvas e cobertura pedológica; e a carta de fragilidade emergente correlaciona às informações resultantes da fragilidade potencial com as informações de uso do solo, indicando os graus de fragilidade das unidades espaciais conforme a proteção do solo, apresentando as áreas em estado de desequilíbrios pela ação antrópica.

Para que essa metodologia seja aplicável, tais variáveis que comporão o estudo deverão compor um banco de dados de um sistema de informações geográficas. Destaca-se o papel de Crepani et al. (1996, 2001) que ajustou a metodologia proposta por Tricart (1977), introduzindo o uso de geotecnologias, notadamente o sensoriamento remoto e os sistemas de informação geográfica, para confeccionar mapas de fragilidade ambiental.

Para Spörl (2004) os estudos relativos à fragilidade dos ambientes são de significativa importância para o planejamento ambiental, pois se trata de um instrumento cuja finalidade é identificar e analisar os ambientes em função de seus diferentes níveis de susceptibilidade. Proporcionando assim, uma melhor definição das diretrizes e ações a serem implementadas no espaço físico- territorial.

Diante do exposto, a hipótese do trabalho parte da possibilidade de se adaptar a metodologia de Ross (1994), a fim de determinar com eficiência os diferentes níveis de fragilidade ambiental em Regiões Metropolitanas. O objetivo do trabalho foi o de adaptar a proposta metodológica de Ross (1994) para novos procedimentos de determinação da fragilidade ambiental, tendo como área de estudo a Região Metropolitana de Aracaju.

\subsection{RECORTE ESPACIAL DA PESQUISA}

Ocupando área de 860,106 km², onde estão inseridos os municípios de Aracaju, Barra dos Coqueiros, Nossa Senhora do Socorro e São Cristóvão, totalizam uma população de 835.816 
habitantes, com uma densidade demográfica de 971,75 hab. $/ \mathrm{km}^{2}$ (IBGE, 2010), dez vezes maior que a densidade demográfica de Sergipe (94,36 hab./km²) (IBGE, 2010) (Figura 01).

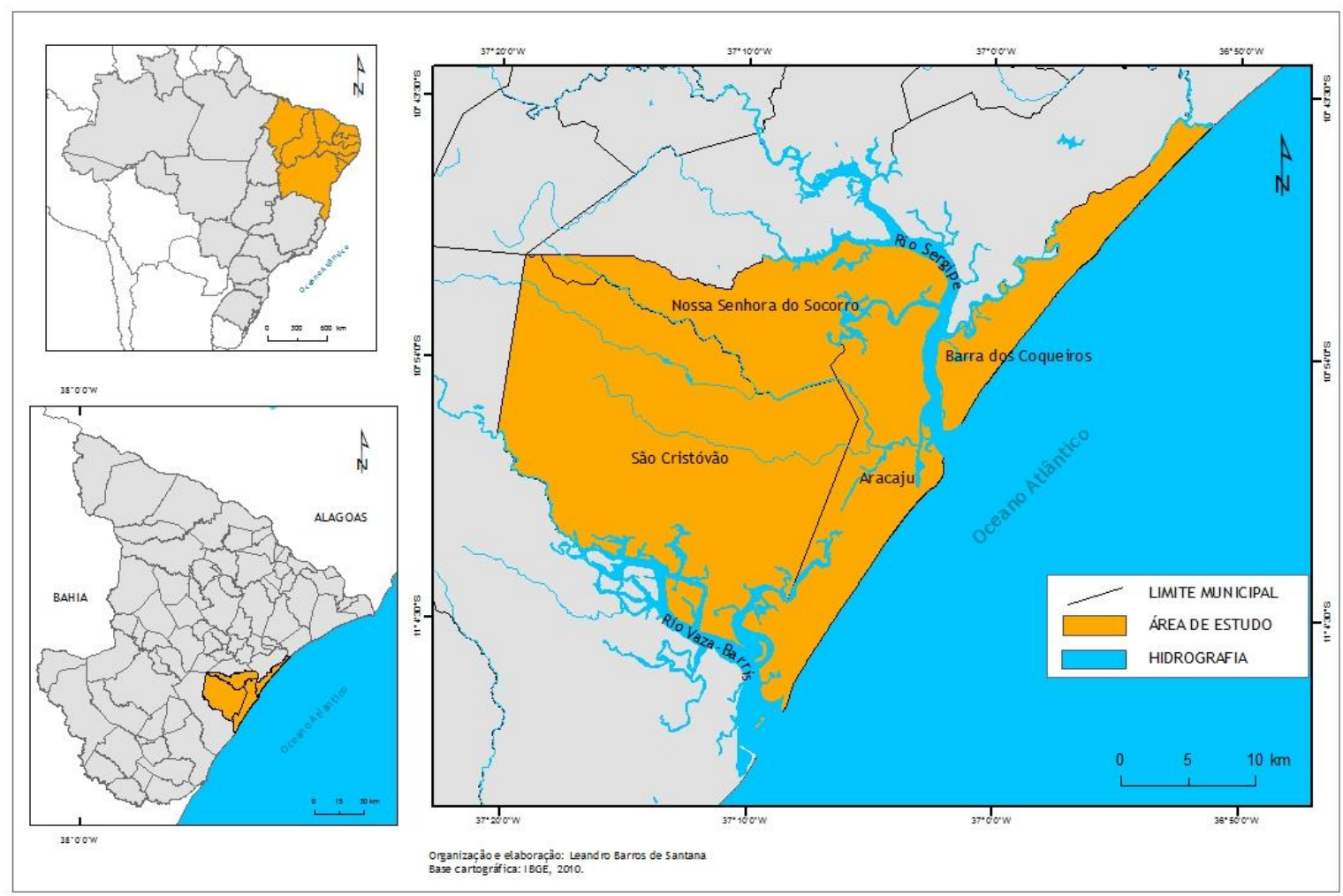

Figura 01: Localização da área de estudo

Fonte: Atlas Digital sobre Recursos Hídricos de Sergipe, 2013

\section{METODOLOGIA}

Os procedimentos técnicos científicos empregados consistem na adaptação da proposta metodológica: Análise Empírica da Fragilidade dos Ambientes Naturais elaborada por Ross (1994) sendo que o peso das variáveis utilizadas a exemplo dos solos, precipitação e litologia foram adaptados da metodologia proposta por Crepani $(1996,2001)$ para que as referências consultadas ficassem coerentes com a área de estudo. Todas as informações cartográficas necessárias foram preparadas em ambiente SIG, sendo espacializadas, utilizando-se o software ArcGIS 10.2.2 Foram gerados os mapas de declividade, litologia, pluviosidade, solos e uso da terra. Tais informações foram retiradas do Atlas Digital sobre Recursos Hídricos produzido pela Secretaria de Meio Ambiente e Recursos Hídricos de Sergipe, atualizado em 2013. Para o estudo climatológico foram utilizados dados diários de precipitação fornecidos pelo Centro de Meteorologia de Sergipe referentes ao período de 1970 a 2011, para os municípios de Aracaju, São Cristóvão, Santo Amaro das Brotas e Itaporanga D’Ajuda, a partir destas informações foram gerados gráficos com a distribuição mensal das precipitações. Para a elaboração do mapa síntese de fragilidade ambiental foram aplicados os métodos de combinação de mapas (álgebra de campo), por meio de 
sobreposição ponderada, disponível no ArcGIS 10.2.2. Primeiro foi feita a conversão dos dados vetoriais para a estrutura matricial (formato tiff.), e posteriormente a reclassificação por meio da ferramenta Spatial Analyst/Reclassify. Na sequência foram executados seguintes procedimentos: Spatial Analyst/Tools/Overlay/Weighted Overlay.

\section{RESULTADOS E DISCUSSÃO}

A região metropolitana de Aracaju está assentada sobre bacia sedimentar de Sergipe representada pelos grupos Sergipe e Piaçabuçu e as Formações Superficiais Continentais com estruturas de idade geológica tercio-quaternárias respectivamente (Quadro 01)

Quadro 01: Unidades litológicas, idade e peso. Fonte: Adaptado Crepani (1996, 2001)

\begin{tabular}{|c|c|c|c|}
\hline $\begin{array}{c}\text { Unidade } \\
\text { litológica }\end{array}$ & Litologia & Idade & Peso \\
\hline ENb (Barreiras) & $\begin{array}{c}\text { Grupo Barreiras - sedimentos areno-argilosos } \\
\text { intercalados com níveis de conglomeráticos. }\end{array}$ & Terciário & 2 \\
\hline $\begin{array}{c}\text { K1ra (Riachuelo - } \\
\text { Angico) }\end{array}$ & $\begin{array}{c}\text { Arenitos brancos, finos e conglomeráticos. Intercalações } \\
\text { de siltito, folhelho e calcário. }\end{array}$ & Mesozóico & 4 \\
\hline K1rm (Maruim) & $\begin{array}{c}\text { Formação Riachuelo - Membro Maruim: calcários, } \\
\text { dolomitos com níveis de arenitos, siltitos e folhelhos. }\end{array}$ & Mesozóico & 4 \\
\hline K1rt (Taquari) & $\begin{array}{c}\text { Formação Riachuelo - Membro Taquari: calcário e } \\
\text { folhelhos interestratificados. }\end{array}$ & Mesozóico & 4 \\
\hline K2ca (Calumbi) & $\begin{array}{c}\text { Argilito e folhelho, cinzentos a esverdeados, com } \\
\text { intercalações de arenitos finos a grossos }\end{array}$ & Mesozóico & 4 \\
\hline K2cta (Aracaju) & $\begin{array}{c}\text { Argilitos cinzentos a verdes, folhelhos castanhos e } \\
\text { margas amareladas }\end{array}$ & Mesozóico & 4 \\
\hline K2cts (Sapucari) & Calcilutitos cinzentos, maciços e/ou estratificados & Mesozóico & 4 \\
\hline NP3eal & Argilitos, siltitos e arenitos feldspáticos e conglomerados & Neoproterozóico & 1 \\
\hline Q12e & $\begin{array}{c}\text { Depósitos eólicos continentais antigos - areias bem } \\
\text { selecionadas com grãos subarredondados }\end{array}$ & $\begin{array}{c}\text { Quaternário- } \\
\text { Pleistoceno }\end{array}$ & 5 \\
\hline Q1tm & $\begin{array}{c}\text { Depósitos de areias litorâneas bem selecionadas - } \\
\text { terraços marinhos pleistocênicos. }\end{array}$ & $\begin{array}{c}\text { Quaternário- } \\
\text { Pleistoceno }\end{array}$ & 3 \\
\hline Q2a & $\begin{array}{c}\text { Depósitos aluvionares e coluvionares arenosos e argilo- } \\
\text { arenosos, localmente com níveis de cascalho }\end{array}$ & $\begin{array}{c}\text { Quaternário- } \\
\text { Holoceno }\end{array}$ & 5 \\
\hline Q2e1 & $\begin{array}{c}\text { Depósitos eólicos litorâneos atuais - areias bem } \\
\text { selecionadas, com grãos arredondados }\end{array}$ & $\begin{array}{c}\text { Quaternário- } \\
\text { Holoceno }\end{array}$ & 5 \\
\hline Q2fl & $\begin{array}{c}\text { Depósitos fluviolagunares -areia e silte argilosos } \\
\text { ricos em matéria orgânica }\end{array}$ & $\begin{array}{c}\text { Quaternário- } \\
\text { Holoceno }\end{array}$ & 5 \\
\hline Depósitos argilo-siltosos ricos em matéria & $\begin{array}{c}\text { Quaternário- } \\
\text { Holoceno }\end{array}$ & 5 \\
\hline comântanos e mangues atuais & Holoceno & 5 \\
\hline
\end{tabular}

A geomorfologia é caracterizada pela presença da planície costeira, com declividades variando de 0 a $6 \%$ (coberta pelos espodossolos, os neossolos quartzarênicos e os neossolos flúvicos) e tabuleiros costeiros (recobertos em sua maior parte pelos argissolos vermelho-amarelo e 
em menor proporção pelos argissolos vermelho-amarelo eutrófico) com declividades variando de 6 a $20 \%$, enquanto os valores superiores a $30 \%$ encontram-se nas vertentes mais íngremes e em áreas de nascentes. (Quadros 02 e 03)

Quadro 02: Classes de declividade, graus de fragilidade e pesos. Fonte: Adaptado de Ross (1994).

\begin{tabular}{|c|c|c|}
\hline Classes de declividade & Graus de Fragilidade & Peso \\
\hline $0 \%$ a $6 \%$ & Muito baixa & 2 \\
\hline $6 \%$ a $12 \%$ & Baixa & 3 \\
\hline $12 \%$ a $20 \%$ & Média & 4 \\
\hline $20 \%$ a $30 \%$ & Alta & 5 \\
\hline
\end{tabular}

\begin{tabular}{|c|c|c|}
\hline Tipos de solo & Graus de Fragilidade & Peso \\
\hline $\begin{array}{c}\text { Argissolos vermelho-amarelo } \\
\text { distrófico }\end{array}$ & Média & 3 \\
\hline Neossolos flúvicos & Muito Alta & 5 \\
\hline Neossolos quartzarênico & Muito Alta & 5 \\
\hline Gleissolos solódico & Muito Alta & 5 \\
\hline Espodossolo & Média & 3 \\
\hline
\end{tabular}

Quadro 03: Tipos de solos, graus de fragilidade e pesos. Fonte: Adaptado de Crepani (1996, 2001).

A vegetação predominante nos estuários dos rios Sergipe e Vaza-Barris são os manguezais, acompanhada da restinga que recobre o litoral e as dunas, já a mata Atlântica aparece em manchas (morro do Urubu, parque do Ibura), por estar em estágio avançado de devastação. O cerrado surge de forma isolada no litoral associado com árvores frutíferas como as mangabeiras, cajueiros, mangueiras (FRANÇA et al, 2008). (Quadro 04)

Quadro 04: Uso da terra, graus de proteção e pesos. Fonte: Adaptado de Ross (1994).

\begin{tabular}{|c|c|c|}
\hline $\begin{array}{c}\text { Uso da Terra e Cobertura } \\
\text { Vegetal }\end{array}$ & Grau de Proteção & Peso \\
\hline $\begin{array}{c}\text { Áreas degradada/úmida/ } \\
\text { urbana/industrial/viveiros e } \\
\text { salinas }\end{array}$ & Muito fraca & 5 \\
\hline $\begin{array}{c}\text { Cultivos agrícolas/solos } \\
\text { expostos /pastagem//dunas e } \\
\text { areial/ }\end{array}$ & Muito fraca & 5 \\
\hline $\begin{array}{c}\text { Vegetação de } \\
\text { restinga/manguezal }\end{array}$ & Muito fraca & 5 \\
\hline Corpos d'água/ & Fraca & 4 \\
\hline $\begin{array}{c}\text { Floresta } \\
\text { estacional/ombrófila/mata ciliar }\end{array}$ & Alto & 2 \\
\hline
\end{tabular}


A análise da distribuição estacional desses municípios utilizando as médias mensais dos postos pluviométricos relacionados ao período analisado indica concentração das chuvas no período outono-inverno, com maiores índices pluviométricos entre os meses de abril a agosto, tais precipitações são consideradas como de caráter frontológico, caracterizando o clima úmido da região (Figura 02 e Quadro 05).
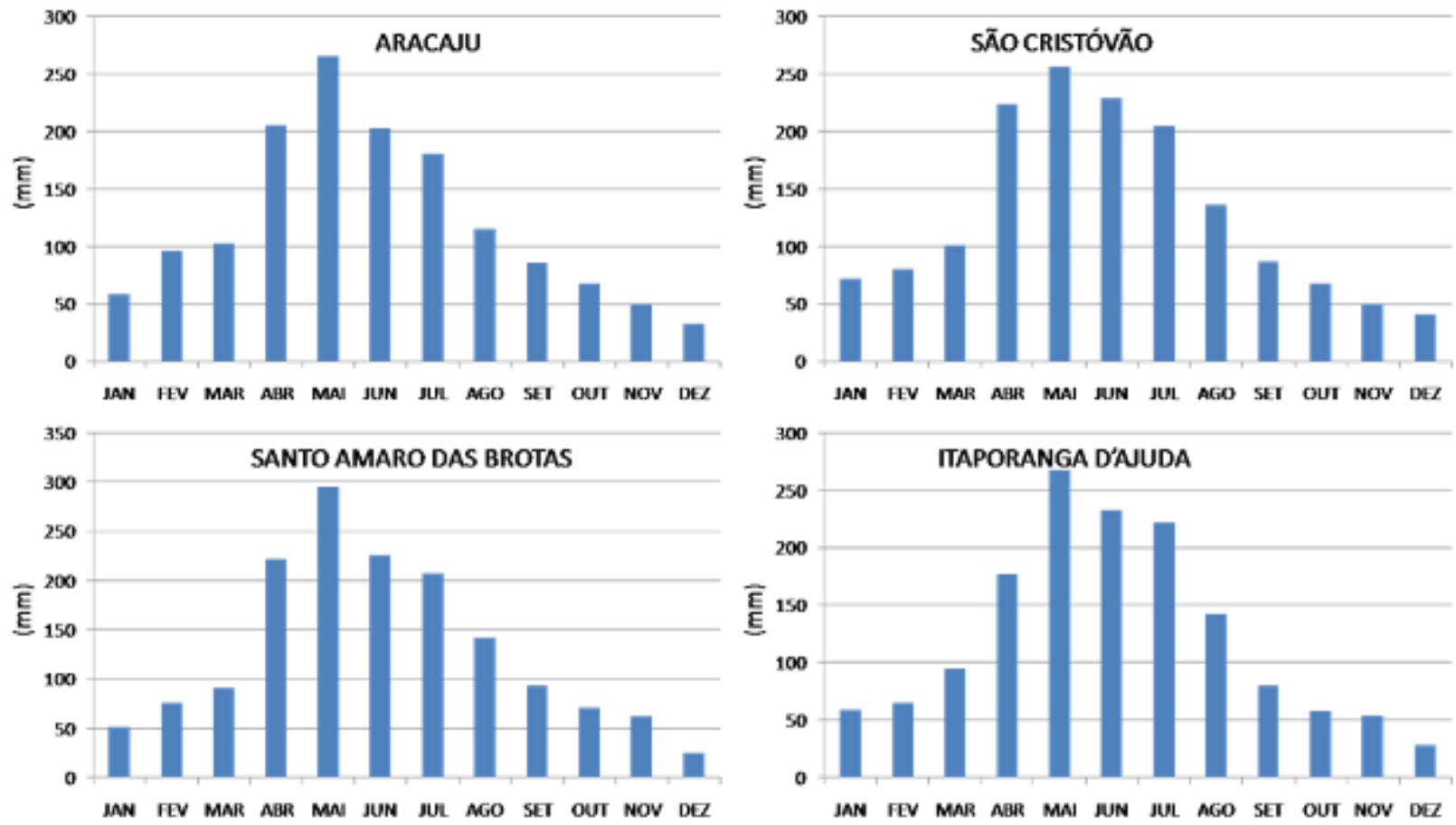

Figura 02: Precipitação média anual dos municípios de Aracaju, São Cristóvão, Santo Amaro das Brotas e Itaporanga da D'Ajuda.

Fonte: CEMESE, dados brutos, 1970 a 2011.

Quadro 05: Precipitação média anual, grau de fragilidade e peso. Fonte: CEMESE 1970 a 2011.

\begin{tabular}{|c|c|c|}
\hline Precipitação média anual & Graus de Fragilidade & Peso \\
\hline $\begin{array}{c}\text { Médias anuais entre os anos de } 1970 \text { a } \\
2011\end{array}$ & Média & 3 \\
\hline
\end{tabular}

A partir da análise das informações anteriormente detalhadas foram gerados mapas com as respectivas fragilidades para cada tema abordado. (Figura 03). 


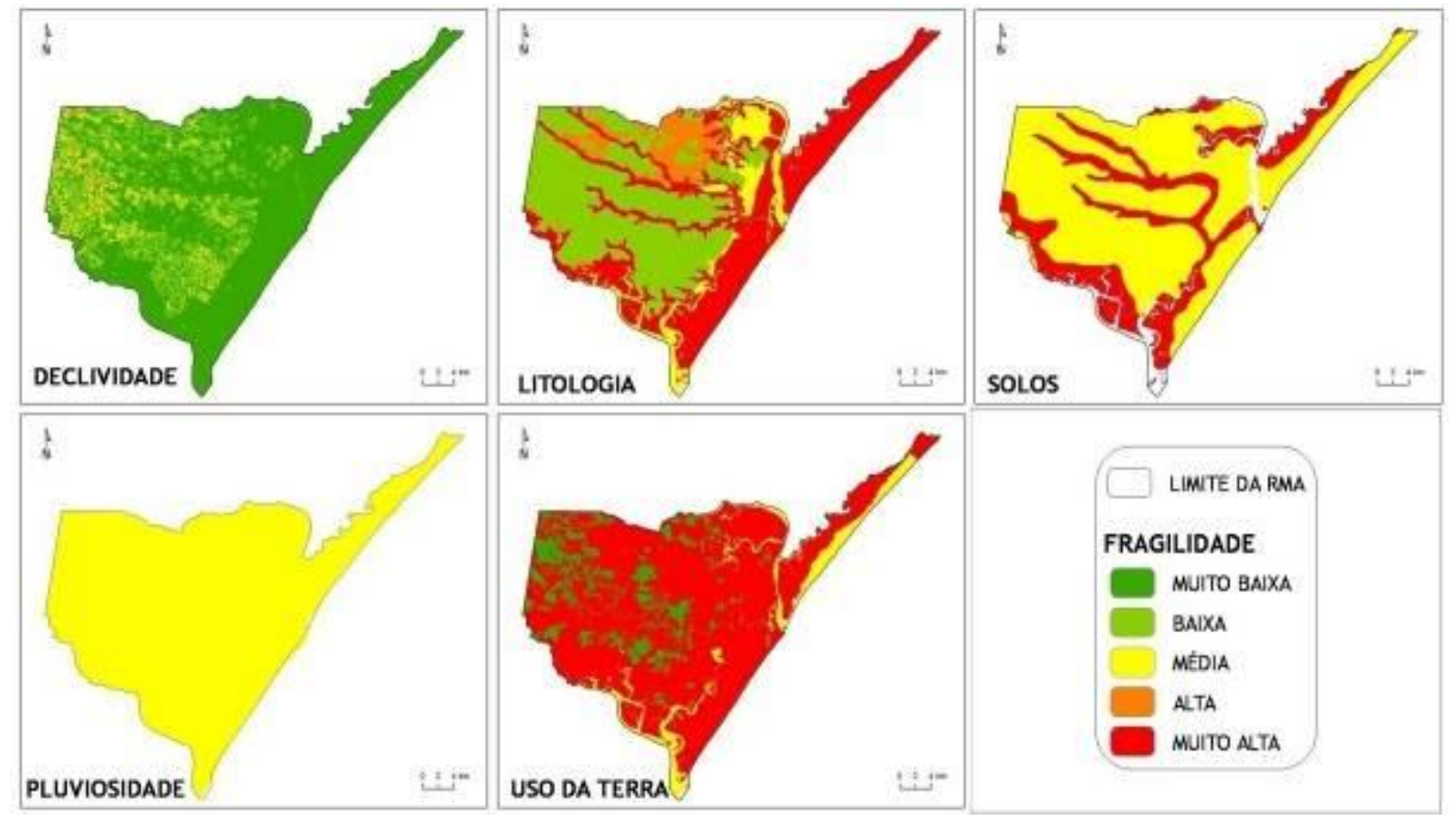

Figura 03: Reclassificação das variáveis.

Fonte: Atlas Digital sobre Recursos Hídricos de Sergipe, 2013.

Com a combinação dos mapas descritos anteriormente obteve-se o mapa de fragilidade potencial com três graus de fragilidade ambiental: a) Baixa, (b) Média, (c) Alta, conforme a figura 04.

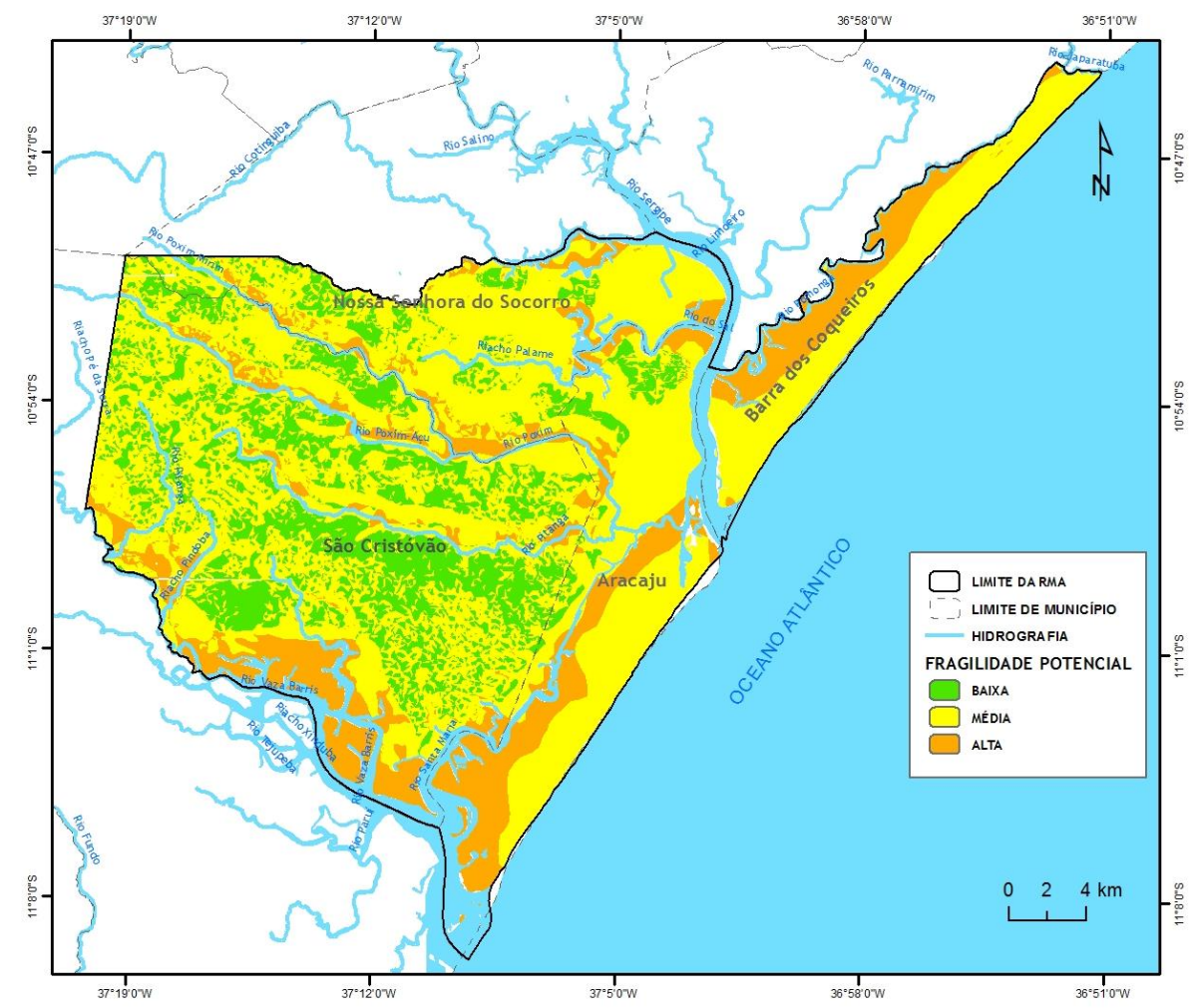


Figura 04: Mapa de fragilidade potencial da Região Metropolitana de Aracaju.

Fonte: Atlas Digital sobre Recursos Hídricos de Sergipe, 2013.

a) Baixa Fragilidade Potencial: A partir da análise do mapa pode-se notar que classe de baixa fragilidade potencial está localizada na unidade geomorfológica sobre a superfície dissecada dos Tabuleiros costeiros com valores de declividades variando de 6 a $12 \%$, recobertos em sua maior parte pelos argissolos vermelho-amarelo derivados dos sedimentos do Grupo Barreiras. Está associado as áreas com resquícios da floresta estacional ombrófila e matas ciliares, com litologias e solos mais resistentes à erosão superficial

b) Média Fragilidade Potencial: esta classe está distribuída espacialmente por quase toda a área da RMA, em associação com os argissolos vermelho-amarelo com declividades variando de 12 a $20 \%$ nos Tabuleiros Costeiros, associados as litologias do grupo Barreiras e das formações arenosas da planície costeira, a exemplo dos terraços marinhos pleistocênicos e das dunas continentais já colonizadas e fixadas pela vegetação de restinga, onde predomina os espodossolos e neossolos quartzarênicos.

c) Alta Fragilidade Potencial: Esta classe está distribuída principalmente ao longo dos principais cursos d'água que drenam a região metropolitana, a exemplo dos rios do Sal, Vaza-Barris, e dos dois principais afluentes do rio Poxim: os rios Poxim-Mirim e PoximAçu associadas as baixas declividades (0 a 6\%), com os neossolos flúvicos e os gleissolos háplicos. Estas características aliadas às precipitações concentradas em curto espaço de tempo, geralmente no outono-inverno transformam-se em áreas suscetíveis à alagamentos, principalmente no município de Aracaju. O fator antrópico potencializa essas fragilidades naturais, pois a região metropolitana abriga a maioria da população sergipana, a saber, pela sua alta densidade demográfica com 971,75 hab./ $\mathrm{km}^{2}$ segundo o último censo (IBGE, 2010) onde a população urbana dos quatro municípios ocupa áreas de alta fragilidade natural.

\section{CONSIDERAÇÕES FINAIS}

A confecção dos produtos cartográficos relacionados às fragilidades potenciais a partir da adaptação das metodologias de Ross (1994) e Crepani $(1996,2001)$ foi fundamental para o entendimento da complexa interação entre os componentes dos sistemas ambientais físicos e socioeconômicos que compõem a Região Metropolitana de Aracaju. Neste trabalho além de utilizar 
os fatores determinados na metodologia de Ross (1994) (declividade e cobertura vegetal/uso da terra), adicionaram-se os fatores pluviosidade e dados de geologia adaptados de Crepani (1996 e 2001), objetivando uma maior diferenciação quanto aos diferentes níveis de fragilidade do ambiente.

Desse modo foi possível identificar as potencialidades naturais da área em questão e compreender que as derivações antropogênicas realizadas, foram capazes de interferir no fluxo energético que mantém o sistema em funcionamento e que já estão desencadeando processos degenerativos ao ambiente natural em alguns locais onde a fragilidade potencial já é elevada, com efeitos para a própria sociedade que ocupa esses locais.

Tal constatação sugere a continuidade do trabalho abordando a fragilidade ambiental a níveis de detalhamento mais profundos, que fornecerá subsídios para que as intervenções vindouras considerem em seus estudos de planejamento o conhecimento das potencialidades e limitações do espaço físico metropolitano de Aracaju.

\section{REFERÊNCIAS}

ALMEIDA, L. Q. Riscos ambientais e vulnerabilidades nas cidades brasileiras: conceitos, metodologias e aplicações. Cultura Acadêmica, São Paulo, 2012

CREPANI, et al. Curso de sensoriamento remoto aplicado ao Zoneamento Ecológico-Econômico. Instituto Nacional de Pesquisas Espaciais, São José dos Campos, 1996.

, Sensoriamento remoto e geoprocessamento aplicados ao Zoneamento Ecológico-Econômico e ao ordenamento territorial. (INPE-8454-RPQ/722). Instituto Nacional de Pesquisas Espaciais, São José dos Campos, 2001.

ENVIRONMENTAL SYSTEMS RESEARCH INSTITUTE (ESRI). ArcGIS Professional GIS for the desktop, versão 10.2.2, 2014.

FRANÇA et al, V.L.A. Atlas escolar de Sergipe: geo-histórico e cultural. Editora Grafset, João Pessoa, 2008.

IBGE. Censo demográfico. Rio de Janeiro, 2010.

JACOBI, P. Impactos socioambientais urbanos - do risco à busca de sustentabilidade. In: Impactos socioambientais urbanos. Editora UFPR, Curitiba, 2004.

ROSS, J. L. S. Análise empírica da fragilidade dos ambientes naturais e antropizados. In: Revista do Departamento de Geografia, no 8. FFLCH-USP. São Paulo, 1994. Paulo, 2006.

Ecogeografia do Brasil: subsídios para planejamento ambiental, Oficina de Textos, São

SERGIPE. Secretaria de Meio Ambiente e Recursos Hídricos. Atlas digital sobre recursos hídricos de Sergipe. Aracaju. CD-ROM, 2013. 
Secretaria de Meio Ambiente e Recursos Hídricos. CEMESE - Centro de meteorologia de Sergipe. Dados brutos, Aracaju, 1970 a 2011.

SPÖRL, C.; ROSS, J. L. S. Análise comparativa da fragilidade ambiental com aplicação de três modelos. GEOUSP - Espaço e Tempo. Número 14, p. 39-49, São Paulo, 2004.

TRICART, J. Ecodinâmica. IBGE, Rio de Janeiro, 1977.

Recebido em: 14/08/2016

Aceito para publicação em: 01/10/2016 